\title{
Impacts of Business Confidence and Consumer Confidence on VN-Index
}

\author{
THÂN TH!̣ THU THỦY \\ University of Economics HCMC - thuynh@ueh.edu.vn \\ PHẠM THỊ BÍCH THẢO \\ Joint Stock Commercial Bank for Investment and Development of Vietnam HCMC Branch - \\ thaoptb@bidv.com.vn
}

\begin{tabular}{|c|c|}
\hline ARTICLE INFO & ABSTRACT \\
\hline 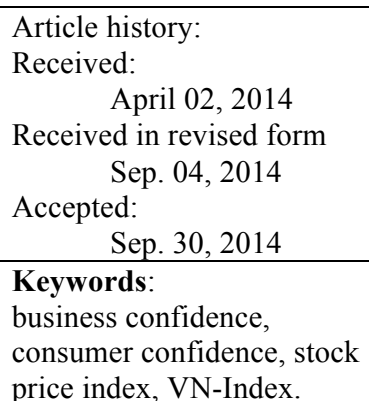 & $\begin{array}{l}\text { Fluctuations in stock price index are always the focus of investors' } \\
\text { and listed companies' interest, so the exploration of factors affecting } \\
\text { this index is crucial. This paper examines the impacts of business } \\
\text { confidence and consumer confidence on VN-Index. The results } \\
\text { confirm positive impacts of business confidence and consumer } \\
\text { confidence on the index, but they are not remarkably high. Thence, } \\
\text { the study proposes solutions to the improvement in business } \\
\text { confidence and consumer confidence to help the Vietnam's stock } \\
\text { market grow in a stable and sustainable manner. }\end{array}$ \\
\hline
\end{tabular}




\section{INTRODUCTION}

A variety of scientific researches in the world emphasizes the impacts of business and consumer confidence on stock price index. Bremmer (2008) studies the relationship between consumer confidence and a set of nine different stock price indices comprising the Dow Jones Industrials; the S\&P500; the Nasdaq 100; the S\&P100; the Russell 1000, 2000 and 3000; and the Wilshire 5000. The Bremmer's study offer four empirical results: "First, consumer confidence and the nine different stock indices are non-stationary time series with unit roots. Second, cointegration tests confirm that there is no long-run relationship between different stock indices and the University of Michigan's measure of consumer confidence. Third, regarding the shortrun relationship between stock indices and consumer confidence, Granger-causality tests indicate that stock prices affect consumer confidence, but consumer confidence does not affect stock prices. Fourth, while expected changes in consumer confidence have no effect on stock prices, unexpected changes in consumer confidence are directly related to changes in stock prices."

Chen (2011) examines the relationship between the lack of consumer confidence and stock returns during market fluctuations. Using the Markov regime-switching model, the study inquires into whether the shock to consumer confidence produces asymmetric effects on stock returns and handles the issue of whether a decrease in consumer confidence drives the stock market into bear territory. Analyzing monthly returns on S\&P500 as empirical evidence, Chen (2011) indicates that decreased consumer confidence has asymmetric effects as well as stronger impacts on the stock returns in the market throughout increases or decreases in stock price indices. Additionally, the market pessimism may easily cause bear territory in which the stock market may endure for a long time, and this affects stock price index and stock returns.

By applying business confidence index as a representative factor, Cevik et al. (2012) explore the impact of business confidence on the U.S. stock returns. Furthermore, to test the possibility of common factors affecting stock returns and business confidence in the US manufacturing sector, the paper carries out estimations with time-varying Markov regime-switching model and the transition equations. Business confidence index, in addition, is concluded to have separate influences on the US stock market in both bull and bear market periods. The findings indicate that business confidence has an impact on the U.S. stock returns. 
Sum (2014) "investigates the joint random effects of business and consumer confidence on stock market returns. Based on the analysis of monthly time series cross-sectional (panel) data from 31 countries, the results show that stock market return goes up by an average of 154 basis points as the change of business confidence increases across time and between countries by one unit when consumer confidence is held constant. Likewise, as the change of consumer confidence increases across time and between countries by one unit, stock market return goes up by an average of 468 basis points while holding business confidence constant. The findings provide empirical evidence of the random effects of business and consumer confidence on stock market returns. The results provide important implication for stock market valuation, investment and risk management." Employing such quantitative factors as business and consumer confidence indices investors could trace certain fluctuations in these to reach at sensible investment decisions.

Accordingly, business and consumer confidence are clearly demonstrated to exert impacts on stock price index and stock market returns. Yet, hardly any research on the same case is found in the current Vietnam's stock market. To clarify this nexus in the context of Vietnam's stock market, hence, the paper explores the model of simultaneous impacts of business and consumer confidence on stock price index listed on HCMC Stock Exchange (VN-Index).

\section{IMPACTS OF BUSINESS CONFIDENCE AND CONSUMER CONFIDENCE ON VN- INDEX}

\subsection{Business Confidence and Consumer Confidence}

Business confidence is perceived in different aspects. According to Financial Times Lexicon, the term refers to "an economic indicator that measures the amount of optimism or pessimism that business managers feel about the prospects of their companies/organizations" and "it also provides an overview of the state of the economy." The U.S. business confidence estimates the optimism of business owners relating to the operation of the economy and the prospects of the enterprises. In Japan, this represents an insight into future direction of investment criteria and the valuation and enterprises' prospects on employment and the entire economy.

Business confidence plays an important role in production and business operation. An increase in this indicator implicates business optimism for the state of production/investment expansion. 
According to Wikipedia, consumer confidence reflects the belief of the consumers in a bright prospect of the economy, personal finance, and employment status. As with its increase, there comes a raise in spending and investment in various channels including securities.

\subsection{Research Model, Research Methodology and Data Selection}

\subsubsection{Research Model}

Adopting the model proposed by Sum (2014) with particular adjustment and adaption, the study brings into focus the effects on stock price index in Vietnam stock market, specifically VN-Index as below:

$\mathrm{P}_{\mathrm{it}}=\beta \triangle \mathrm{BC}_{\mathrm{it}}+\gamma \triangle \mathrm{CC}_{\mathrm{it}}+\varepsilon_{\mathrm{it}}$

Where:

$\mathrm{P}_{\mathrm{it}}$ : VN-Index;

$\triangle \mathrm{BC}_{\mathrm{it}}$ : difference in the value of business confidence index of the current month compared to the previous one;

$\triangle \mathrm{CC}_{\text {it: }}$ difference in the value of consumer confidence index of the current month compared to the previous one;

$\varepsilon_{\mathrm{it}}$ error terms.

\subsubsection{Research Methodology}

Strengths and appropriateness offered by Ordinary Least Square (OLS) allow the study to proceed with the regression analysis and other relevant tests.

\subsubsection{Data Collection Method}

The data employed in the current study consist of: (1) business confidence index, (2) consumer confidence index, and (3) VN-Index series, all of which were collected in the period from Q3/2008 to the end of Q2/2013 to ensure the compatibility of existing data sets (VN-Index series have been publicized since July 28, 2000 while business confidence index and consumer confidence index were officially established as from Q3/2008).

\section{Database}

VN-Index: daily price index is calculated by an average of opening and closing prices on HOSE from July 1, 2008 and monthly price index is the average price of the days within a month. 
Business confidence: Database is based on the survey findings and quarterly issues of Vietnam World Vest Base (WVB), specializing in surveys on VN's business confidence, and collection was scheduled to commence from Q3/2008. Data on business confidence are issued each quarter, but data for the model are issued each month, which results in the following data approximation technique: months of the same quarter come up with similar values. The difference of the index is then calculated, equaling the previous month's index subtracted from that of the later one.

Consumer confidence: The database is extracted from survey data and quarterly issues by Nielsen Vietnam, a global information and measurement company with leading market positions in marketing and consumer information, along with assessment of consumer-based sensitivity, future consumer confidence with specific spending and saving trends. Due to its quarterly issuance, consumer confidence index allows data estimation, following the same technique as applied to business confidence.

\section{RESULTS AND DISCUSSION}

\subsection{Reality of Vietnam Business Confidence}

Performance of many enterprises was recovered by the end of the first half of 2013, yet in reality the economy experienced a slow recovery and their unsaleable stock remained rather large. Meanwhile, purchasing power might not have been prospering, which made enterprises reluctant to increase their investment. The 2013 business confidence rose more sharply than that in 2012. However, the business confidence only increased sharply for large companies with strong brand names and development potentials. Small and medium ones were still enduring economic slump.

Table 1. VN's Business Confidence in the Period Q3/2008 - Q2/2013 (Point)

\begin{tabular}{cccc}
\hline Quarter & $\begin{array}{c}\text { Vietnam business confidence } \\
\text { index }\end{array}$ & Quarter & $\begin{array}{c}\text { Vietnam business } \\
\text { confidence index }\end{array}$ \\
\hline $3 / 2008$ & 100 & $1 / 2011$ & 109 \\
$4 / 2008$ & 93 & $2 / 2011$ & 88 \\
$1 / 2009$ & 99 & $3 / 2011$ & 123 \\
$2 / 2009$ & 130 & $4 / 2011$ & 116 \\
$3 / 2009$ & 136 & $1 / 2012$ & 113
\end{tabular}




$\begin{array}{llll}4 / 2009 & 135 & 2 / 2012 & 120 \\ 1 / 2010 & 138 & 3 / 2012 & 107 \\ 2 / 2010 & 134 & 4 / 2012 & 83 \\ 3 / 2010 & 137 & 1 / 2013 & 114 \\ 4 / 2010 & 126 & 2 / 2013 & 118\end{array}$

Source: Vietnam World Vest Base (WVB)

\subsection{Reality of Vietnam Consumer Confidence}

The impact of global economic crisis knocked Vietnamese economy off its balance from Q3/2008, and its current health, despite a gradual recovery, is still perceived as weak by Vietnamese consumers. Prospects for employment status have improved, particularly for the first six months of 2013, which is subject to an increase in consumer confidence index compared to that of 2012. Nevertheless, efficient consumption on essential goods is prioritized.

Table 2. Vietnam's Consumer Confidence in the Period Q3/2008 - Q2/2013 (Point)

\begin{tabular}{cccc}
\hline Quarter & $\begin{array}{c}\text { Vietnam's consumer } \\
\text { confidence index }\end{array}$ & Quarter & $\begin{array}{c}\text { Vietnam's consumer } \\
\text { confidence index }\end{array}$ \\
\hline $3 / 2008$ & 97 & $1 / 2011$ & 98 \\
$4 / 2008$ & 91 & $2 / 2011$ & 97 \\
$1 / 2009$ & 85 & $3 / 2011$ & 96 \\
$2 / 2009$ & 85 & $4 / 2011$ & 99 \\
$3 / 2009$ & 109 & $1 / 2012$ & 94 \\
$4 / 2009$ & 109 & $2 / 2012$ & 95 \\
$1 / 2010$ & 101 & $3 / 2012$ & 87 \\
$2 / 2010$ & 119 & $4 / 2012$ & 88 \\
$3 / 2010$ & 88 & $1 / 2013$ & 96 \\
$4 / 2010$ & 103 & $2 / 2013$ & 95 \\
\hline
\end{tabular}

Source: Data collected by Nielsen Vietnam

\subsection{Research Results}

3.3.1. Description of Samples 
Descriptive statistics of the samples are employed to determine number of observations, mean, and standard deviation, thereby identifying their distinctive values.

Table 3. Descriptive Statistics of Number of Observations, Mean, and Standard Deviation

\begin{tabular}{cccc}
\hline Variable & Observations & Mean & Standard Deviation \\
\hline $\mathrm{P}_{\mathrm{it}}$ & 59 & 886.8081 & 137.3983 \\
$\triangle \mathrm{BC}_{\mathrm{it}}$ & 59 & 0.305085 & 9.300082 \\
$\triangle \mathrm{CC}_{\mathrm{it}}$ & 59 & -0.03898 & 6.451319 \\
\hline
\end{tabular}

Source: Synthesis of the authors' findings

VN-Index reveals a monthly average of 886 points, which is relatively high and is explained by the fact that 2008 Vietnam's stock market was in a stage of development, whereas the later years indicate market declines and no vivid uptrend.

Vietnam's monthly business and consumer confidence was shown to exhibit low and even negative indices, which is due to the difference between the later month's indices and those of the previous one taken in the study, resulting in incorrect reflection of mean values. These values, nevertheless, partly suggest that both business and consumer confidence in the studied phases are pessimistically assessed, the cause of which is the 2008 global financial crisis with its lasting impact on Vietnam's economy

Not many existing observations are accounted for by data collection; business confidence and consumer confidence, despite the establishment of Vietnam's stock market in 2000, were officially surveyed and issued from Q3/2008. Hence, for data compatibility, the study could not gather data for a longer period.

\subsubsection{Stationarity Test}

OLS method requires that mean and variance not change with time, and to meet such, data series must be stationary. Unit root test is accordingly conducted. Taking the difference (first-order, second-order, etc.) proceeds with non-stationary data series until the appearance of stationary ones, which are employed in subsequent regressions.

To-be-tested hypotheses:

$\mathrm{H}_{0}$ : Data series are non-stationary.

$\mathrm{H}_{1}$ : Data series are stationary. 


$$
\alpha=0.05
$$

Stationarity tests are performed on the following data series: difference in business confidence index, consumer confidence index and VN-Index.

Table 4. Stationarity Test on Data Series (\%)

\begin{tabular}{cc}
\hline Data series & p-value \\
\hline $\mathrm{P}_{\text {it }}$ & 0.3130 \\
$\triangle \mathrm{BCC}_{\mathrm{it}}$ & 0.0000 \\
$\triangle \mathrm{CC}_{\text {it }}$ & 0.0000 \\
\hline
\end{tabular}

Source: Synthesis of the authors' findings

As p-value of difference in business confidence index and consumer confidence index, as illustrated by the test, is less than $\alpha(5 \%), \mathrm{H}_{0}$ is rejected and both differences are stationary. VN-Index, due to its value larger than $\alpha(5 \%)$, suggests that $\mathrm{H}_{0}$ is accepted and the data series are non-stationary. Thus, another stationarity test on its first-order difference should be performed. The results indicate the first-order difference with $\mathrm{p}$-value $=0,0000(<\alpha)$, thereby rejecting $\mathrm{H}_{0}$ and accepting $\mathrm{H}_{1}$. Accordingly, the first-order difference of VN-Index is stationary.

After the stationary tests, regressions and such other tests for multicollinearity, heteroskedasticity, and autocorrelation of the data series are carried out, and none of the phenomena is found.

\subsubsection{Results of OLS Regression}

The regression model applied to the dataset indicates that an increase in business confidence by $1 \%$ compared to the previous month's rate leads to that in VN-Index by $1.5533 \%$, i.e. there exists a positive impact, the level of which otherwise cannot be measured. Similarly, a $1 \%$ increase in the coefficient of the difference in consumer confidence entails an increase of $0.1717 \%$ in VN-Index (another positive impact). These results, therefore, suggest the same case of positive impacts of both business and consumer confidence indexes on VN-Index. While the impact of the former is more significant, its significance is less than $100 \%$ and R-squared is only $4.38 \%$. 
Additionally, the examination of statistical significance of the coefficients via pvalue demonstrates that most values are higher than $\alpha$ (or 5\%); thus, the study is considered not highly statistically significant.

Table 5. Data Series Regression Model

\begin{tabular}{ccccc}
\hline \multicolumn{1}{c}{ Variable } & Coefficient & Std. Error & t-Statistic & Prob. \\
\hline C & -0.802328 & 9.670297 & -0.082968 & 0.9342 \\
KD & 1.553316 & 1.015233 & 1.530009 & 0.1321 \\
TD & 0.171727 & 1.461772 & 0.117479 & 0.9069 \\
\hline R-squared & 0.043812 & Mean dependent var. & & -0.410060 \\
Adjusted R-squared & 0.007036 & S.D. dependent var. & & 71.94421 \\
S.E. of regression & 71.69066 & Akaike info criterion & & 11.43560 \\
Sum squared resid & 267256.6 & Schwarz criterion & & 11.54509 \\
Log likelihood & -311.4790 & Hannan-Quinn criter. & & 11.47794 \\
F-statistic & 1.191319 & Durbin-Watson stat & & 1.479266 \\
Prob(F-statistic) & 0.311975 & & \\
\hline
\end{tabular}

Source: Synthesis of the authors' findings

Lower significance level can also be explained by data collection. Once more, the study carries out another estimation of business and consumer confidence indices, guided by the following technique: for months in the same quarter with the same values, average value of the months is taken by making two-month moving average calculation, and then working out the difference between monthly indices and performing regression analysis to investigate whether the later impacts as well as significance levels of the variables are higher than the original ones.

Applying the calculations, the study's following phase features the same steps as described in the previous regression and finds no stated phenomena.

Results of the two-month moving average calculation suggest that coefficients of business confidence and consumer confidence as well as the significance level increase from $4.38 \%$ to $10.41 \%$. In addition, $\mathrm{p}$-value of the coefficients reveals higher statistical significance as compared to $\alpha=5 \%$, and particularly $p$-value of business confidence index decreases, equaling 0.05 . 
Table 6. Regression Model with Two-Month Moving Average Calculation

\begin{tabular}{lcccc}
\hline \multicolumn{1}{c}{ Variable } & Coefficient & Std. Error & t-Statistic & Prob. \\
\hline C & -0.917578 & 9.541181 & -0.096170 & 0.9238 \\
KD & 2.770408 & 1.403644 & 1.973726 & 0.0538 \\
TD & 2.648724 & 2.020282 & 1.311066 & 0.1957 \\
\hline R-squared & 0.104105 & Mean dependent var & & -0.248374 \\
Adjusted R-squared & 0.068972 & S.D. dependent var & & 72.60967 \\
S.E. of regression & 70.06093 & Akaike info criterion & & 11.39056 \\
Sum squared resid & 250335.2 & Schwarz criterion & & 11.50106 \\
& & & \\
Log likelihood & -304.5451 & Hannan-Quinn criter. & & 11.43318 \\
F-statistic & 2.963155 & Durbin-Watson stat & & 1.564044 \\
Prob(F-statistic) & 0.060612 & & \\
\hline
\end{tabular}

Source: Synthesis of the authors' findings

3.3.4. Overall Assessment of Impacts of Business Confidence and Consumer Confidence on $V N$-Index

First, regarding the relationship between business/consumer confidence and VNIndex, the values of the differences in the model denotes the impacts of both kinds of confidence on the latter.

Next, concerning the tendency of business/consumer confidence's effect, positive signs of the values imply that an increase in business/consumer confidence makes VNIndex rise.

Then, the existence of impacts can be confirmed yet it is extremely hard to clarify its extent (percentage of increase/decrease in VN-Index under the influence of $1 \%$ increase in the values of business/consumer confidence) due to the non-stationary VNIndex dataset which results in the application of regression to the case of first-order difference.

Additionally, given the magnitude of coefficients of business/consumer confidence, much higher coefficients of difference in business confidence than those of difference in consumer confidence indicate that impact of business confidence on VN-Index is 
more profound than that of consumer confidence. Thence, to boost VN-Index, it is vital to find measures to enhance business confidence, which could help investors, make rational decisions on their investment.

Last, in comparison with the value $100 \%$, R-squared is not high enough, which suggests that the use of business and consumer confidence to predict the increase/decrease in VN-Index is not highly effective. There should accordingly be other factors' contribution toward reinforcing R-square and thereby enhancing predictability of the model.

\section{CONCLUSION AND SOLUTIONS TO ENHANCE BUSINESS AND CONSUMER CONFIDENCE}

\subsection{Conclusion}

Results of regression models illustrate positive impacts of business and consumer confidence on VN-Index and the impact of business confidence is greater than that of consumer confidence. However, the paper does not offer high predictability and statistical significance due to the research data published by World Vest Base Vietnam and Nielsen Vietnam. Yet, values of all months of the same quarter are assumed to be equal in order to ensure the research model's compatibility. Thus, bias between months, upon the calculations of the difference between indices, creeps in and affects the research results. Another likely limitation is that Vietnam's stock market perhaps reflects impacts of other factors on fluctuations in VN-Index as individual investors account for over $80 \%$ of total number of investors with limited capital, featuring crowd's purchasing behaviors.

\subsection{Solutions}

Through analyses and estimation of the impacts of enterprises' business and consumer confidence indices on VN-Index, the paper comes up with several solutions to enhance business and consumer confidence and thereby to raise stock price index. In addition to macroeconomic solutions for economic stability and development such as inflation restraint, forex reserves stabilization and enhancement, etc., it is also necessary to focus on the following microeconomic measures that directly affect enterprises and consumers:

- Reducing production costs: to increase consumption in the current situation, enterprises should make an innovation in models, technological process and apply scientific-technical advances to improve products' quality and reduce prices. 
Moreover, enterprises in their production must strictly manage the inputs to optimally reduce production costs.

- Increasing competitiveness: in the process of global and regional economic integration, enterprises need focus on the following four aspects: capital, technology, human resources, brand and/or prestige apart from increasing competitiveness by exploiting strengths and overcoming drawbacks.

- Creating consumer confidence: this is a motivation and prerequisite for enterprises' development and success as well as encouragement to reach their set targets.

- Considering consumption: people's consumption needs to be fully attended in the current economic crisis. Therefore, enterprises should create consumer confidence, which bolsters long-term consumption of enterprises' goods, output issues and production scale-up.

- Decreasing essential costs: the long-lasting economic crisis leads to an increase in living costs and causes difficulties to social life as a whole. Once the cost is high, consumers tend to reduce their spending and the confidence in the future economic development is not maintained at a high degree. Thus, government should make the interventions to stabilize the prices of essential goods and services, and restrict enterprises' monopoly in products and public services.

- Improving the labor market and raising income: to boost consumption, employment should be improved to increase income. Positive changes in the labor market would account for considerable income raise, promotion of consumer confidence, especially consumers' spending for shopping, followed by production growth that creates high motivation as well as confidence for enterprises

\section{References}

Bremmer, D. (2008), "Consumer Confidence and Stock Prices", presented during session \#10e, Beliefs, Preferences and Stock Prices, at the $72^{\text {nd }}$ annual meeting of the Midwest Economics Association Hyatt Regency, Chicago, Illinois.

Cevik, E., T. Korkmaz \& E. Atukeren (2012), "Business Confidence and US Stock Returns: A Time-Verying Markov Regime-Switching Approach", Applied Financial Economics, 12(4): 299-312. 
Chen, S. S. (2011), "Lack of Consumer Confidence and Stock Returns", Journal of Empirical Finance, 18(2): 225-236.

Financial Times (2013), "Definition of business confidence", available at http://lexicon.ft.com/ Term?term=business-confidence.

Nielsen Company (2013), “Các giải pháp” available at www.nielsen.com/vn/vi

Sum, V. (2014), "Effects of Business and Consumer Confidence on Stock Market Returns: CrossSectional Evidence", Economics, Management, and Financial Markets, 9(1): 21-25.

Wikipedia (2014), “Consumer Confidence Index" available at http://en.wikipedia.org/ wiki/Consumer_confidence_index.

World Vest Base VN (2013), "Vietnam’s Business Confidence Index”, unpublished raw data. 